\title{
Context-dependent functions of specific microRNAs in neuronal development
}

\author{
Fen-Biao Gao
}

\begin{abstract}
MicroRNAs (miRNAs) are small noncoding RNAs that regulate multiple developmental processes at the posttranscriptional level. Recent rapid progresses have demonstrated critical roles for a number of miRNAs in neuronal development and function. In particular, miR-9 and miR-124 are specifically expressed in the mammalian nervous system, and their respective nucleotide sequences are 100\% identical among many species. Yet, their expression patterns and mRNA targets are less conserved throughout evolution. As a consequence, these miRNAs exhibit diverse context-dependent functions in different aspects of neuronal development, ranging from early neurogenesis and neuronal differentiation to dendritic morphogenesis and synaptic plasticity. Some other neuronal miRNAs also exhibit context-dependent functions in development. Thus, post-transcriptional regulation of spatial and temporal expression levels of protein-coding genes by miRNAs contributes uniquely to the proper development and evolution of the complex nervous system.
\end{abstract}

\section{Background}

MicroRNAs (miRNAs) are small, noncoding RNAs (21 to 24 nucleotides) that are processed from hairpin structures derived from endogenously transcribed primary miRNAs (pri-miRNAs) [1,2]. As part of Argonaute complexes, these small RNAs regulate gene expression at the post-transcriptional level through imperfect baseparing with specific sequences, located mostly in the $3^{\prime}$ UTRs and, in some cases, in the $5^{\prime}$ UTRs or the coding regions [3-6]. Each miRNA is predicted to regulate up to hundreds of mRNAs [7]. These miRNA-target interactions often result in mRNA degradation but, under certain circumstances, may also increase the translation of some target mRNAs $[6,8,9]$.

Since the first miRNA was discovered in Caenorhabditis elegans in 1993 [10], and the second miRNA along with its evolutionary conservation in 2000 [11,12], hundreds of miRNAs have been identified. miRNAs have been implicated in almost all aspects of cellular processes, including developmental timing, tumorigenesis, immunity, neuronal development, and neurodegeneration [13-18]. These regulatory small RNAs can function as developmental switches or fine-tuning systems to ensure robustness $[19,20]$. In some other cases, loss of

Correspondence: fen-biao.gao@umassmed.edu

Departments of Neurology and Neurobiology, University of Massachusetts Medical School, Worcester, MA 01605, USA individual miRNAs does not seem to lead to any gross developmental defects but may reveal specific functions under sensitized genetic backgrounds [21].

In the nervous system, recent studies in several model organisms demonstrate critical roles for a number of miRNAs in neuronal development or function. For instance, Lsy- 6 and miR-273 are engaged in a feedback loop in specifying the cell fate of two chemosensory neurons in C. elegans [22]. miR-7 promotes photoreceptor neuron differentiation through modulating components in the epidermal growth factor receptor signaling pathway in Drosophila [23]. In mammals, miR-134 plays a prominent role in regulating dendritic spine morphogenesis through LIM domain kinase 1 (Limk1) [24] and members of the miR-200 family are involved in the terminal differentiation of olfactory precursors [25]. Interestingly, miR-134 also regulates sirtuin 1 (SIRT1)mediated synaptic plasticity and memory formation [26] and embryonic stem cell differentiation [27], suggesting miRNAs can exert developmental and cellular contextdependent functions. Consistent with this notion, multiple functions of miR-132 have been revealed. miR-132 is regulated by the cAMP response element binding protein (CREB) and in turn affects neurite outgrowth through the Rho family GTPase activating protein p250GAP [28]. miR-132 also modulates the circadian clock located in the suprachiasmatic nucleus [29] as well 
as antiviral innate immunity in monocytes and primary lymphatic endothelial cells [30]. Moreover, miR-138 is involved in both spine morphogenesis [31] and cardiac patterning [32].

In this review, I will focus on miR-9 and miR-124, two miRNAs that are specifically expressed in the mammalian nervous system. They are highly conserved at the nucleotide sequence level in different species yet exert diverse context-dependent functions through different mRNA targets. Thus, as the most extensively studied neuronal miRNAs, their roles in various aspects of neuronal development in different species will serve as an excellent case study to elucidate the functional conservation and divergence of neuronal miRNAs during evolution.

\section{miR-9 and miR-124: mammalian brain-specific miRNAs}

miR-9 (also known as miR-9a in Drosophila) was first identified in Drosophila [33] and its authenticity and conservation were confirmed by its identification in mouse brains [34-36]. miR-9 is highly conserved at the nucleotide sequence level from flies to humans but not in C. elegans. In Drosophila embryos, miR-9 is highly expressed in ectodermal epithelial cells, with little or no expression in the central nervous system $[37,38]$. In contrast, miR-9 in rodents is specifically expressed in the brain but not other tissues; in the brain, it is broadly expressed in neuronal precursors and also at lower levels in some postmitotic neurons [34-36]. Thus, although this miRNA is highly conserved at the nucleotide level, its tissue-specific expression pattern is not.

In mammals, miR-9 is processed from three precursors that are encoded by three genes located on different chromosomes. However, in flies, there is only one miR-9 gene. In mouse embryos at embryonic day 10.5 (E10.5), pre-miR-9-2 is expressed at a much higher level than pre-miR-9-3, and pre-miR-9-1 expression is barely detectable [39]. Similarly, pre-miR-9-2 is expressed at high levels in human neural progenitor cells (hNPCs) derived from human embryonic stem cells (hESCs), while pre-miR-9-1 is almost undetectable [40]. In the developing mouse brain or zebrafish nervous system, miR-9 is also encoded by multiple genes and is broadly expressed, mostly in proliferating progenitor cells but it is also detectable in differentiated neurons [41-44]. It remains to be determined whether different miR-9 precursors may be expressed through distinct transcriptional controls in different subset of cells or at slightly different developmental stages. If that is the case, the presence of multiple genes encoding the same mature miRNA may confer another layer of regulation.

miR-124 (also known as miR-124a) was first identified as one of the mouse brain-specific miRNAs [34], and its nucleotide sequence is conserved from Aplysia, Drosophila, and C. elegans to mammals $[35,37,45,46]$. It is the most abundant miRNA in the brain, where it accounts for an estimated $25 \%$ to $48 \%$ of all miRNAs [34]. miR124 is upregulated during neuronal differentiation of certain cell lines and hESCs and during mouse embryonic brain development $[35,36,40,47]$. miR-124 is widely expressed in virtually all postmitotic neurons in the adult mouse brain, but its expression is relatively low in the ventricular zones in the embryonic mouse brain [41]. Similarly, miR-124 is expressed in all differentiating cells throughout the larval zebrafish brain and retina [42] and in all differentiating and mature neurons in chick spinal cord [48,49]. Interestingly, in Aplysia, miR124 is expressed at a high level in sensory neurons but is almost undetectable in motor neurons [45], suggesting functional divergence of this miRNA in different species. Like miR-9, miR-124 is encoded by one gene in some other model organisms but by three genes located on three different chromosomes in mammals. Although, like many other miRNAs, the nucleotide sequence of miR-124 precursors (pre-miR-124) is also poorly conserved in different species, they all maintain the stemloop structures that produce the highly conserved mature miR-124.

\section{miR-9 in early neurogenesis}

Detailed in situ hybridization reveals a dynamic expression profile for miR-9 during mouse corticogenesis. One of the most striking features is the reciprocal gradient of miR-9 and forkhead box protein G1 (foxg1) mRNA expression in E12 developing telencephalon [39]. Foxg1, a transcription factor that promotes the proliferation of cortical progenitor cells [50], is present throughout the telencephalon, but its expression gradually decreases in the medial pallium, where miR-9 is intensely expressed, raising the possibility that miR-9 may negatively regulate foxg1 expression [39]. Indeed, the foxg1 3' UTR contains an evolutionarily conserved miR-9 binding site and seems to be a direct target of miR-9. In P19-derived cells or in E12.5 neocortex, miR-9 knockdown increases Foxg1 expression, while overexpression of miR-9 decreases the protein levels of Foxg1 but not Nr2E1 (Nuclear receptor subfamily 2, group E member 1; also known as the human homologue of the Drosophila tailless gene (TLX)). Such a miRNA-target interaction supports the notion that miR-9 promotes the generation of Cajal-Retzius cells in the medial pallium of developing telencephalon [39] (Figure 1A). It will be interesting to confirm such a regulatory role for miR-9 in this developmental process in vivo using genetic approaches.

In zebrafish, miR-9 seems to affect early brain patterning through a different set of targets. Loss of both maternal and zygotic Dicer in zebrafish does not affect 

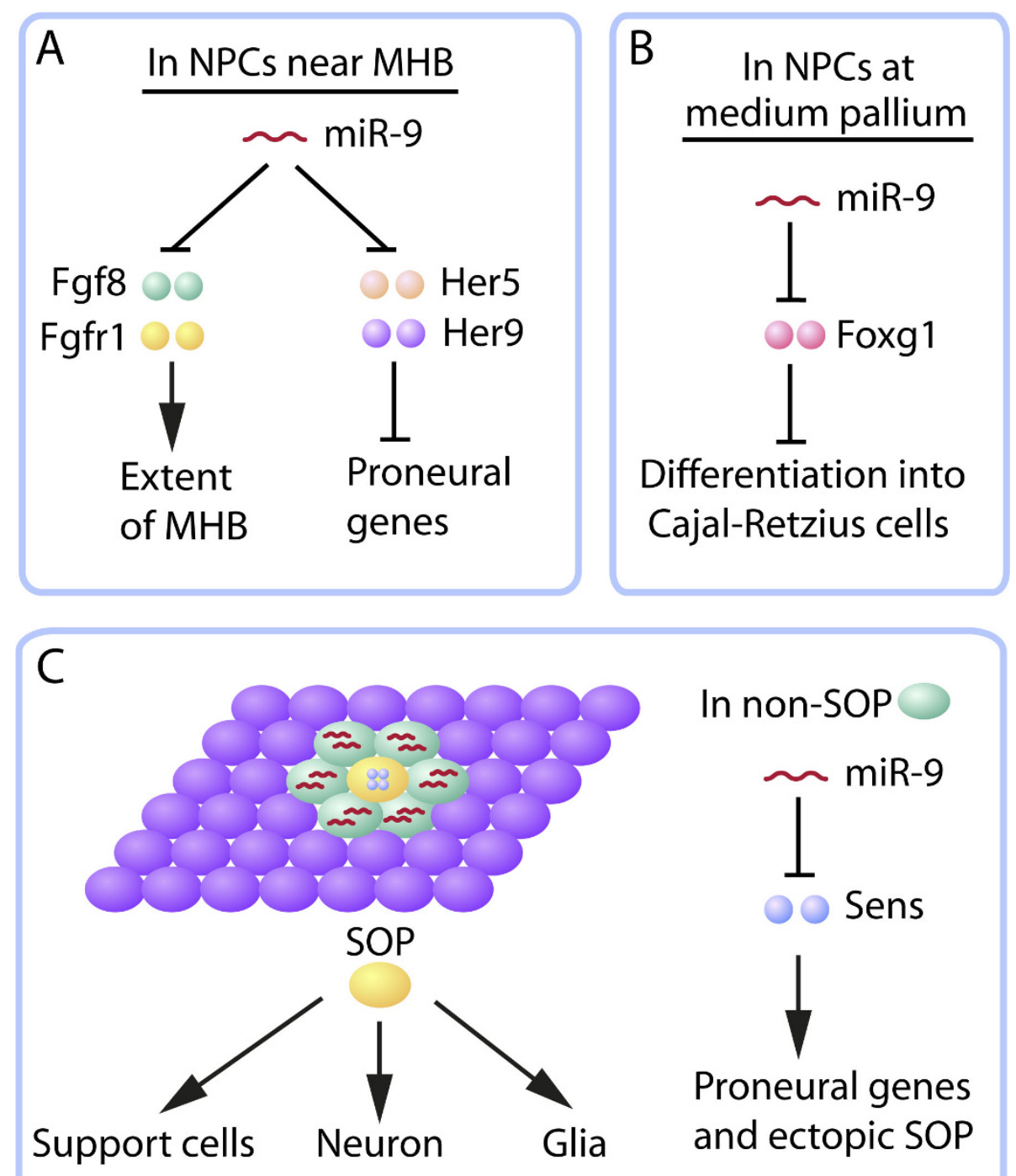

Figure 1 Context-dependent functions of miR-9 in neurogenesis. (A,B) In the developing brains of zebrafish (A) and mice (B), miR-9 is expressed in neural progenitor cells (NPCs) and promotes neurogenesis by downregulating different suppressors of neuronal differentiation. (C) During early neurogenesis in Drosophila embryos, miR-9 is not expressed in sensory organ precursors (SOPs) that eventually give rise to sensory neurons and other cell types. Instead, it is expressed in non-SOP cells, including those adjacent to the SOP in the pro-neural cluster, to suppress the residual expression of Sens, an activator of proneural genes in the process of lateral inhibition. Fgf, fibroblast growth factor; Fgfr, fibroblast growth factor receptor; Foxg1, forkhead box protein G1; MHB, midbrain-hindbrain boundary.

axis formation and differentiation of different cell types but causes abnormal morphogenesis of the developing brain [51], suggesting individual miRNAs may play finetuning functions. Indeed, miR-9 is widely expressed in neural progenitor cells in the developing zebrafish neural tube but is absent at the midbrain-hindbrain boundary (MHB) [44], an organizing center to specify the tectum at its rostral side and the cerebellum at its caudal side [52]. miR-9 seems to simultaneously target several components in the fibroblast growth factor signaling pathway, which is highly active in the MHB and restricts its patterning activity [44] (Figure 1B). miR-9 also regulates the expression of Her5 and Her9 during neuronal differentiation [44]. Both loss- and gain-offunction studies reveal that miR-9 restricts the organizing activity of the MHB and promotes neurogenesis in the midbrain-hindbrain region near the MHB.

The role of miR-9 in early neurogenesis is drastically different in Drosophila (where the gene is called miR$9 a$ ). Although the miR-9 nucleotide sequence is $100 \%$ conserved among many species, miR-9a shows little expression in the nervous system of developing Drosophila embryos; rather, it is highly expressed in ectodermal epithelial cells and in wing disc cells but not in 
sensory organ precursor (SOP) cells $[37,38]$. Thus, transcriptional regulation of $m i R-9$ expression is not evolutionarily conserved. SOPs, which give rise to sensory neurons and supporting glial cells, are generated through a process called lateral inhibition, which involves the Notch signaling pathway and has been used as a model system for studying early neurogenesis [53]. Loss of miR-9a does not affect the viability of the mutant flies but increases the production of SOPs [38] (Figure 1C). The effects of miR-9 on SOP specification are not highly penetrant, again supporting the notion that many miRNAs are not absolute developmental switches. In flies, unlike in vertebrates, key targets of miR-9 are dLMO (Drosophila LIM only protein) $[54,55]$ and Senseless (sens) [38,55] (Figure 1C), a zinc finger transcription factor downstream of Notch [56]. Since miR-9 binding sites in the sens 3' UTR are not conserved in mammals, the shift in miR-9 targets may explain in part its diverse functions in different model organisms [57].

\section{miR-9 in stem cell-derived neural progenitor cells}

miR-9 is upregulated during in vitro neural differentiation of mouse ESCs [58] and adult neural stem/progenitor cells [59], and during the maturation of hNPCs derived from hESCs [40]. Thus, miR-9 is expected to modulate the cellular behavior of stem cell-derived NPCs. Indeed, manipulation of miR-9 activity in mouse ESCs in vitro affects the ratio of differentiated neurons versus glia cells [58]. Similarly, overexpression of miR-9 in adult NPCs promotes neuronal differentiation and migration. However, inhibition of miR-9 activity does not affect the neuronal differentiation of adult NPCs [59], even though it impairs the generation of Cajal-Retzius neurons in embryonic mouse brains [39]. This discrepancy could be explained by the difference in the cellular context or some other unknown reasons. One target that mediates the effects of miR-9 overexpression on adult NPCs is TLX, a nuclear receptor required to maintain self-renewal of adult NPCs [59]. Interestingly, the transcription of pri-miR-9-1 also seems to be regulated by TLX, thus forming a potential feedback regulatory loop. However, if the relative levels of three pre-miR-9 genes in adult NPCs are similar to those in embryos, the change in total mature miR-9 level as regulated by this loop would be marginal because pre-miR-9-1 accounts for less than $5 \%$ of miR-9 precursors [39].

During neural differentiation of hESCs, miR-9 is not detectable in embryoid bodies and rosette structures; its expression is turned on at the onset of hNPC formation and increases gradually during hNPC maturation [40]. Inhibition of miR-9 activity in early hNPCs enhances migration and reduces proliferation without precocious differentiation. In this case, stathmin, which promotes microtubule instability [60], seems to be a key target required to mediate the effect of loss of miR-9. Partial suppression of stathmin by small interfering RNA rescues the effects of loss of miR-9 on the migration of early hNPCs in vitro and in vivo when transplanted into mouse embryonic brains or adult brains of a mouse model of stroke [40]. Thus, miR-9 may play distinct roles in NPCs of different developmental stages and origins.

\section{miR-124 in neuronal differentiation}

The striking upregulation of miR-124 during neuronal differentiation $[35,36]$ raises the possibility that this most abundant brain-specific miRNA may play unique functions during this process. Indeed, many targets of miR-124 that positively or negatively regulate neuronal differentiation have been identified. Ectopic expression of miR-124 in HeLa cells suppresses the expression of a large number of non-neuronal transcripts, leading to the hypothesis that one of miR-124's primary functions is to maintain neuronal identity by downregulating non-neuronal mRNAs [61]. Consistent with this notion, some of these targets are upregulated in postmitotic rodent neurons when miR-124 is knocked down, and miR-124 expression in non-neuronal cells and neural progenitor cells is suppressed by the RE1 silencing transcription factor (REST) [47]. Similarly, miR-124 directly targets the mRNA of polypyrimidine tract-binding protein 1 (PTBP1), a global repressor of alternative splicing in non-neuronal cells, leading to a more neuron-specific alternative splicing pattern [62]. In chick spinal cord, the mRNA of small C-terminal domain phosphatase 1 (SCP1) seems to be complementary to that of miR-124 in the developing spinal cord [49]. miR-124 also downregulates other endogenous targets during neuronal differentiation, such as laminin $\gamma 1$ and integrin $\beta 1$ in developing chick spinal cord [48] and ephrin-B1 in developing mouse cortex [63]. In the subventricular zone of the adult mouse brain, miR-124 is upregulated during the transition from transit-amplifying cell to neuroblasts, and its expression in neuroblasts increases further at cell cycle exit [64]. During this process, the high mobility group box transcription factor Sox9 seems to be a key target of miR-124 [64]. Evidently, miR-124 regulates different targets during neuronal differentiation in a cellular context-dependent manner.

Several miR-124-target interactions have been well established, but their relevance to a discernable developmental phenotype is less clear. miR-124 promotes neuronal differentiation in developing chick spinal cord, as shown by overexpression or 2'-OMe antisense knockdown experiments [49]. However, a similar study using the same assay system did not observe such an effect 
[48]. Although several reports indicate that ectopic overexpression of miR-124 promotes neuronal differentiation from progenitor cells $[49,58,62-65]$, the precise roles of endogenous miR-124 in this developmental process remain to be further elucidated. In vitro acute knockdown of miR-124 in ephrin-B1 (EfnB1) $)^{-1-}$ NPCs modestly inhibited their neuronal differentiation [63]. In vivo knockdown of miR-124 in the subventricular zone of adult mice decreased the number of newly generated postmitotic neurons by $30 \%$ [64], suggesting an instructive role for miR-124 in promoting adult neurogenesis. In contrast, genetic ablation of miR-124 in C. elegans altered gene expression but did not result in any obvious defects in sensory neuron differentiation [66]. More sensitive assays and readouts are needed to further understand the subtle but apparently important functions of miR-124 in neuronal differentiation, especially using loss-of-function mutants in different model organisms.

\section{miR-9 and miR-124 in dendritic branching}

Conditional knockout of Dicer in excitatory forebrain neurons in mice reduces dendritic branch elaboration [67]. In Drosophila, terminal dendritic branches of Dicer1 mutant sensory neurons exhibit growth defects [68], and loss of Dicer-1 or Pasha in Drosophila olfactory projection neurons leads to a specific dendritic targeting defect [69]. Although Dicer may process other classes of RNAs, these findings raise the possibility that at least some miRNAs participate in the molecular regulation of dendritic morphogenesis. Indeed, both loss- and gain-of function studies of cultured developing cortical or hippocampal neurons indicate a role for miR-132 in basal and activity-dependent dendritic growth and branching $[28,70]$. As the most abundant brain miRNA whose expression persists throughout adult life, miR-124 seems to promote neurite outgrowth in differentiating mouse P19 cells, possibly in part by regulating members of the Rho GTPase family [71]. However, ectopic expression of miR-132 or miR-124 had no effect on dendritic growth or arborization of hippocampal neurons that had been cultured in vitro for 14 days [72]. The latter result could be explained by the high levels of these miRNAs already present in mature neurons in culture. The involvement of the miR-124-target interaction in dendritic morphogenesis is further revealed by manipulating the 3' UTR of BAF53b, a key component of the ATP-dependent chromatin-remodeling complexes [73]. Loss of the miR-124 and miR-9* binding sites in the BAF53a 3' UTR inhibited activity-dependent dendritic growth in cultured hippocampal neurons, while expression of BAF53b with the wild-type BAF53a 3' UTR failed to produce such an inhibition [73]. Thus, miR-124 downregulates BAF53a, which in turn leads to increased activity-dependent dendritic growth.

Ectopic expression of miR-124 in developing Drosophila sensory neurons suppresses dendritic branching [68]. The different effects of miR-124 in P19 cells versus fly neurons may reflect the difference in mRNA targets in different cell types. However, the precise roles of endogenous miR-124 in dendritic development await further investigation once miR-124 mutant flies or knockout mice become available. In contrast to miR124, ectopic expression of miR-9 in fly sensory neurons increases dendritic branching [68], suggesting that different miRNAs can exert opposite effects on this developmental process through distinct subsets of target mRNAs. Whether endogenous miR-9 in mammalian neurons also regulates dendritic morphogenesis remains to be seen.

\section{miR-9 and miR-124 in synaptic plasticity and brain function}

Synaptic formation and plasticity play central roles in neuronal connectivity and brain function, and miRNAs seem to be well positioned to regulate this important process [74]. Indeed, loss of Dicer in vivo not only reduces dendritic branching but also affects spine morphology [67], although the interpretation of this result is complicated by the cell death phenotype caused by conditional loss of Dicer in certain neurons $[67,75,76]$. Moreover, several miRNAs have been implicated in spine morphogenesis and synaptic plasticity in C. elegans, Drosophila, and mammals, including miR-134 [24], let-7 [77,78], miR-284 [79], miR-1 [80], miR-138 [31], miR-206 [81], and miR-125a [72].

This rapidly expanding list also includes miR-124, which in Aplysia, in stark contrast to that in other model organisms, does not seem to be expressed ubiquitously and constitutively in all neurons [45]. In Aplysia sensory-motor neuron co-culture, a model system for studying short- and long-term memory [82], miR-124 is rapidly downregulated by the neurotransmitter serotonin. This downregulation is relevant to synaptic plasticity because manipulating miR-124 levels in sensory neurons directly affects long-term facilitation at the sensory-motor synapse [45]. One of the predicted mRNA targets of miR-124 is CREB1, a transcriptional activator required for long-term facilitation [83]. Indeed, the expression of Aplysia CREB1 is directly inhibited by miR-124, and miR-124 suppresses serotonin-induced synaptic facilitation through downregulation of CREB1 [45]. The miR-124 binding site is conserved in the mammalian CREB1 3' UTR. Whether CREB-mediated signaling and synaptic functions are regulated by miR124 in the mouse brain remains to be experimentally 
validated. Interestingly, miR-124 and other neuronal miRNAs have a much shorter half-life than that in nonneuronal cells and their abundance in mammalian neurons is regulated by neuronal activity [84]. Further investigation of the underlying mechanism will be of great importance.

In the adult rat brain, miR-124 is significantly downregulated after cocaine administration, suggesting that this miRNA may be involved in cocaine-induced plasticity, possibly through CREB, brain-derived neurotrophic factor (BDNF), or other potential targets [85]. Similarly, miR-9 is expressed in supraoptic nucleus neurons and striatal neurons in the rat brain, as detected by singlecell PCR, and alcohol increases miR-9 expression in both of these cell types [86]. miR-9 downregulates specific mRNA splice variants of the large conductance calcium- and voltage-activated potassium (BK) channel, contributing to the development of alcohol tolerance [86]. Thus, the BK channel is a key target of miR-9 in drug adaptation and adult brain plasticity.

The potential involvement of miRNAs in age-dependent neurodegeneration is increasingly appreciated [18]. For instance, several miRNAs suppress the neurotoxicity of atrophin 1 in spinocerebellar ataxia 1 (SCA1) pathogenesis in a combinatorial manner [87]. miR-206 plays an active role in delaying the disease progress of amyotrophic lateral sclerosis [81], a fatal disease caused by motor neuron degeneration in which dysregulation of the miRNA pathway may be one of the most significant pathogenic mechanisms [88]. Interestingly, miR-9 is significantly reduced in a genetic model of spinal motor neuron disease [89]. Similarly, miR-9 levels are lower in patient brains affected by Huntington's disease [90], and miR-29a/b-1 expression is reduced in the brains of patients with sporadic Alzheimer's disease [91]. Whether these brain-specific miRNAs contribute to the pathogenesis of some age-dependent neurodegenerative diseases remain to be further investigated.

\section{Conclusions}

Although a few miRNAs can function as developmental 'switches' similar to transcription factors to fundamentally affect cell fate, such as in the specification of chemosensory neurons in C. elegans [19] and some aspects of cardiovascular development [92], many other miRNAs, such as miR-9 and miR-124, individually exert a more modest effect on neuronal development. Another similarity between the two most extensively studied neuronal miRNAs is their modest effects on gene expression, consistent with recent reports that many if not all miRNAs mostly induce less than twofold changes in target gene expression $[93,94]$. Thus, these miRNAs may serve as an important buffering system to ensure the precision of gene regulation and tissue homeostasis in developing and adult brains.

Both miR-9 and miR-124 are implicated in multiple stages of neuronal development. It is intriguing that, in some instances, miR-124 and miR-9 are needed to act cooperatively with each other $[58,73]$ and as parts of regulatory feedback loops involving REST [47,90]. Although these regulatory networks can be quite complicated with multiple transcription factors and miRNAs involved, a recurring theme seems to be that one or a few mRNA targets account for the majority of the phenotype in a particular developmental or cellular process (Tables 1 and 2). This is likely the case for many other miRNAs as well. The context-dependent functions of miRNAs in neuronal development or other processes could be explained in part by the variations in transcriptome composition in diverse cell types in different species. The ratio of copy numbers between a specific miRNA and its target may also influence its developmental functions. Thus, it will be useful to systematically identify context-dependent targets of a specific miRNA, such as using an in vivo crosslinking and immunoprecipitation (CLIP) approach [95,96]. Moreover, it is critically important to study the endogenous activities of specific miRNAs in their physiological contexts, and

Table 1 mRNA targets and functions of miR-9 in neuronal development and function

\begin{tabular}{|c|c|c|c|}
\hline Functions & Species & Targets & References \\
\hline Suppresses excess SOP production & D. melanogaster & Sens & {$[38,55]$} \\
\hline Promotes dendritic branching & D. melanogaster & $?$ & [68] \\
\hline Restricts the extent of MHB & Zebrafish & FGF8, FGFR1 & [44] \\
\hline Promotes neuronal differentiation near MHB & Zebrafish & Her5, Her9 & [44] \\
\hline Limits the generation of Cajal-Retzius cells & Rodent & Foxg1 & [39] \\
\hline Promotes neuronal differentiation from adult neural stem/progenitor cells & Rodent & TLX & [59] \\
\hline Enhances alcohol tolerance in adult brains & Rodent & BK channels & [86] \\
\hline Inhibits astroglial cell differentiation & Rodent & $?$ & [58] \\
\hline Promotes proliferation but limits migration of hESC-derived young hNPCs & Human & Stathmin & [40] \\
\hline May contribute to neurodegenerative diseases & Human & NEFH, REST & {$[89,90]$} \\
\hline
\end{tabular}

BK channel, large conductance calcium- and voltage-activated potassium channel; FGF, fibroblast growth factor; FGFR, fibroblast growth factor receptor; Foxg1, forkhead box protein G1; hESC, human embryonic stem cell; hNPC, human neural progenitor cell; MHB, midbrain-hindbrain boundary; NEFH (neurofilament heavy polypeptide); REST, RE1 silencing transcription factor; SOP, sensory organ precursor; TLX, human homologue of the Drosophila tailless gene. 
Table 2 mRNA targets and functions of miR-124 in neuronal development and function

\begin{tabular}{|c|c|c|c|}
\hline Functions & Species & Targets & References \\
\hline Inhibits long-term facilitation at the sensory-motor synapses & Aplysia & CREB & [45] \\
\hline Suppresses dendritic branching by overexpression & D. melanogaster & $?$ & [68] \\
\hline Promotes neuronal differentiation in spinal cord & Chick & SCP1 & [49] \\
\hline Promotes neurite growth & P19 cells & RhoA & [71] \\
\hline Involved in BAF53b-induced activity-dependent dendritic growth & Rodent & BAF53b & [73] \\
\hline Promotes neuronal differentiation in developing brain & Rodent & REST, PTBP1, Ephrin-B1 & {$[62-64]$} \\
\hline Promotes adult neurogenesis & Rodent & Sox9 & [65] \\
\hline Promotes neuronal differentiation & Rodent & $?$ & {$[58]$} \\
\hline Cocaine-induced plasticity in the adult brain & Rodent & CREB, BDNF & [85] \\
\hline
\end{tabular}

BDNF, brain-derived neurotrophic factor; CREB, CAMP response element binding protein; PTBP1, polypyrimidine tract-binding protein 1; REST, RE1 silencing transcription factor; SCP1, small C-terminal domain phosphatase 1.

results obtained from heterologous assay systems need to be interpreted with sufficient caution.

Although only a limited number of miRNAs have been studied for their endogenous functions in the nervous system, the importance of this class of regulatory molecules in the construction of neuronal circuits is becoming increasingly evident. Intriguingly, despite evolutionary conservation at the nucleotide level, the expression patterns and regulatory targets of many miRNAs shifted during evolution. miR-9 and miR-124 are among the most ancient animal miRNAs that show cell-type specific expression and may play key roles in the development of new body plans [97]. Thus, conserved neuronal miRNAs may assume novel functions, which, together with newly evolved miRNAs, such as those uniquely expressed in the human brain [98], may contribute to the evolution of this most complex yet poorly understood organ.

\section{Abbreviations \\ BK: channel, large conductance calcium- and voltage-activated potassium channel; CREB: CAMP response element binding protein; E: embryonic day; Foxg1: forkhead box protein G1; hESC: human embryonic stem cell; hNPC: human neural progenitor cell; MHB: midbrain-hindbrain boundary; miRNA: microRNA; pri-miRNA: primary microRNA; REST: RE1 silencing transcription factor; SOP: sensory organ precursor; TLX: human homologue of the Drosophila tailless gene; UTR: untranslated region.}

\section{Acknowledgements}

I thank lab members for discussions and S Ordway for editorial assistance. This work is supported by start-up funds from the University of Massachusetts Medical School and a grant (NS066586) from the NIH (F-BG).

\section{Competing interests}

The author declares he has no competing interests.

Received: 29 July 2010 Accepted: 1 October 2010 Published: 1 October 2010

\section{References}

1. Ambros V: microRNAs: tiny regulators with great potential. Cell 2001, 107:823-826.

2. Kim VN, Han J, Siomi MC: Biogenesis of small RNAs in animals. Nat Rev Mol Cell Biol 2009, 10:126-139.
3. Filipowicz W, Bhattacharyya SN, Sonenberg N: Mechanisms of posttranscriptional regulation by microRNAs: Are the answers in sight? Nat Rev Genet 2008, 9:102-114.

4. Lytle JR, Yario TA, Steitz JA: Target mRNAs are repressed as efficiently by microRNA-binding sites in the $5^{\prime}$ UTR as in the $3^{\prime}$ UTR. Proc Natl Acad Sci USA 2007, 104:9667-9672

5. Tay Y, Zhang J, Thomson AM, Lim B, Rigoutsos I: MicroRNAs to Nanog, Oct4 and Sox 2 coding regions modulate embryonic stem cell differentiation. Nature 2008, 455:1124-1128.

6. Ørom UA, Nielsen FC, Lund AH: MicroRNA-10a binds the 5'UTR of ribosomal protein mRNAs and enhances their translation. Mol Cell 2008, 30:460-471.

7. Lewis BP, Burge CB, Bartel DP: Conserved seed pairing, often flanked by adenosines, indicates that thousands of human genes are microRNA targets. Cell 2005, 120:15-20.

8. Guo H, Ingolia NT, Weissman JS, Bartel DP: Mammalian microRNAs predominantly act to decrease target mRNA levels. Nature 2010, 466:835-840

9. Vasudevan S, Tong Y, Steitz JA: Switching from repression to activation: microRNAs can up-regulate translation. Science 2007, 318:1931-1934

10. Lee RC, Feinbaum RL, Ambros V: The C. elegans heterochronic gene lin-4 encodes small RNAs with antisense complementarity to lin-14. Cell 1993, 75:843-854.

11. Reinhart BJ, Slack FJ, Basson M, Pasquinelli AE, Bettinger JC, Rougvie AE, Horvitz HR, Ruvkun G: The 21-nucleotide let-7 RNA regulates developmental timing in Caenorhabditis elegans. Nature 2000, 403:901-906.

12. Pasquinelli $A E$, Reinhart $B J$, Slack $F$, Martindale $M Q$, Kuroda MI, Maller $B$, Hayward DC, Ball EE, Degnan B, Müller P, Spring J, Srinivasan A, Fishman M, Finnerty J, Corbo J, Levine M, Leahy P, Davidson E, Ruvkun G: Conservation of the sequence and temporal expression of let-7 heterochronic regulatory RNA. Nature 2000, 408:86-89.

13. Ambros V: Control of developmental timing in Caenorhabditis elegans. Curr Opin Genet Dev 2000, 10:428-433.

14. Inui M, Martello G, Piccolo S: MicroRNA control of signal transduction. Nat Rev Mol Cell Biol 2010, 11:252-263.

15. O'Connell RM, Rao DS, Chaudhuri AA, Baltimore D: Physiological and pathological roles for microRNAs in the immune system. Nat Rev Immunol 2010, 10:111-122.

16. Coolen M, Bally-Cuif L: MicroRNAs in brain development and physiology. Curr Opin Neurobiol 2009, 19:461-470.

17. Schratt G: Fine-tuning neural gene expression with microRNAs. Curr Opin Neurobiol 2009, 19:213-219.

18. Hébert SS, De Strooper B: Alterations of the microRNA network cause neurodegenerative disease. Trends Neurosci 2009, 32:199-206.

19. Hobert O: Gene regulation by transcription factors and microRNAs. Science 2008, 319:1785-1786.

20. Herranz $H$, Cohen SM: MicroRNAs and gene regulatory networks: managing the impact of noise in biological systems. Genes Dev 2010, 24:1339-1344 
21. Brenner $J L$, Jasiewicz $K L$, Fahley AF, Kemp BJ, Abbott AL: Loss of individual microRNAs causes mutant phenotypes in sensitized genetic backgrounds in C. elegans. Curr Biol 2010, 20:1321-1325.

22. Hobert $\mathrm{O}$ : Architecture of a microRNA-controlled gene regulatory network that diversifies neuronal cell fates. Cold Spring Harb Symp Quant Biol 2006, 71:181-188.

23. Li X, Carthew RW: A microRNA mediates EGF receptor signaling and promotes photoreceptor differentiation in the Drosophila eye. Cell 2005 123:1267-1277.

24. Schratt GM, Tuebing F, Nigh EA, Kane CG, Sabatini ME, Kiebler M, Greenberg ME: A brain-specific microRNA regulates dendritic spine development. Nature 2006, 439:283-289.

25. Choi PS, Zakhary L, Choi WY, Caron S, Alvarez-Saavedra E, Miska EA, McManus M, Harfe B, Giraldez AJ, Horvitz HR, Schier AF, Dulac C: Members of the miRNA-200 family regulate olfactory neurogenesis. Neuron 2008, 57:41-55.

26. Gao J, Wang WY, Mao YW, Gräff J, Guan JS, Pan L, Mak G, Kim D, Su SC, Tsai LH: A novel pathway regulates memory and plasticity via SIRT1 and miR-134. Nature 2010, 466:1105-1109.

27. Tay Y, Zhang J, Thomson AM, Lim B, Rigoutsos I: MicroRNAs to Nanog, Oct4 and Sox2 coding regions modulate embryonic stem cell differentiation. Nature 2008, 455:1124-1128.

28. Wayman GA, Davare $M$, Ando $H$, Fortin D, Varlamova O, Cheng HY, Marks D, Obrietan K, Soderling TR, Goodman RH, Impey S: An activityregulated microRNA controls dendritic plasticity by down-regulating p250GAP. Proc Natl Acad Sci USA 2008, 105:9093-9098.

29. Cheng HY, Papp JW, Varlamova O, Dziema H, Russell B, Curfman JP, Nakazawa T, Shimizu K, Okamura H, Impey S, Obrietan K: MicroRNA modulation of circadian-clock period and entrainment. Neuron 2007, 54:813-829.

30. Lagos D, Pollara G, Henderson S, Gratrix F, Fabani M, Milne RS, Gotch F, Boshoff C: MiR-132 regulates antiviral innate immunity through suppression of the p300 transcriptional co-activator. Nat Cell Biol 2010, 12:513-519.

31. Siegel G, Obernosterer G, Fiore R, Oehmen M, Bicker S, Christensen M, Khudayberdiev S, Leuschner PF, Busch CJ, Kane C, Hübel K, Dekker F, Hedberg C, Rengarajan B, Drepper C, Waldmann H, Kauppinen S, Greenberg ME, Draguhn A, Rehmsmeier M, Martinez J, Schratt GM: A functional screen implicates microRNA-138-dependent regulation of the depalmitoylation enzyme APT1 in dendritic spine morphogenesis. Nat Cell Biol 2009, 11:705-716.

32. Morton SU, Scherz PJ, Cordes KR, Ivey KN, Stainier DY, Srivastava D: microRNA-138 modulates cardiac patterning during embryonic development. Proc Natl Acad Sci USA 2008, 105:17830-17835.

33. Lagos-Quintana M, Rauhut $R$, Lendeckel W, Tuschl T: Identification of novel genes coding for small expressed RNAs. Science 2001, 294:853-858.

34. Lagos-Quintana M, Rauhut R, Yalcin A, Meyer J, Lendeckel W, Tuschl T: Identification of tissue-specific microRNAs from mouse. Curr Biol 2002, 12:735-739.

35. Krichevsky AM, King KS, Donahue CP, Khrapko K, Kosik KS: A microRNA array reveals extensive regulation of microRNAs during brain development. RNA 2003, 9:1274-1281.

36. Sempere LF, Freemantle S, Pitha-Rowe I, Moss E, Dmitrovsky E, Ambros V: Expression profiling of mammalian microRNAs uncovers a subset of brain-expressed microRNAs with possible roles in murine and human neuronal differentiation. Genome Biol 2004, 5:R13.

37. Stark A, Brennecke J, Bushati N, Russell RB, Cohen SM: Animal MicroRNAs confer robustness to gene expression and have a significant impact on 3'UTR evolution. Cell 2005, 123:1133-1146.

38. Li Y, Wang F, Lee JA, Gao FB: MicroRNA-9a ensures the precise specification of sensory organ precursors in Drosophila. Genes Dev 2006, 20:2793-2805.

39. Shibata M, Kurokawa D, Nakao H, Ohmura T, Aizawa S: MicroRNA-9 modulates Cajal-Retzius cell differentiation by suppressing Foxg1 expression in mouse medial pallium. J Neurosci 2008, 28:10415-10421.

40. Delaloy C, Liu L, Lee JA, Su H, Shen F, Yang GY, Young WL, Ivey KN, Gao FB: MicroRNA-9 coordinates proliferation and migration of human embryonic stem cell-derived neural progenitors. Cell Stem Cell 2010, 6:323-335.
41. Deo M, Yu JY, Chung KH, Tippens M, Turner DL: Detection of mammalian microRNA expression by in situ hybridization with RNA oligonucleotides. Dev Dyn 2006, 235:2538-2548.

42. Wienholds E, Kloosterman WP, Miska E, Alvarez-Saavedra E, Berezikov E, de Bruijn E, Horvitz HR, Kauppinen S, Plasterk RH: MicroRNA expression in zebrafish embryonic development. Science 2005, 309:310-311.

43. Kapsimali M, Kloosterman WP, de Bruijn E, Rosa F, Plasterk RH, Wilson SW: MicroRNAs show a wide diversity of expression profiles in the developing and mature central nervous system. Genome Biol 2007, 8 : R173.

44. Leucht C, Stigloher C, Wizenmann A, Klafke R, Folchert A, Bally-Cuif L: MicroRNA-9 directs late organizer activity of the midbrain-hindbrain boundary. Nat Neurosci 2008, 11:641-648.

45. Rajasethupathy P, Fiumara F, Sheridan R, Betel D, Puthanveettil SV, Russo JJ, Sander C, Tuschl T, Kandel E: Characterization of small RNAs in Aplysia reveals a role for miR-124 in constraining synaptic plasticity through CREB. Neuron 2009, 63:803-817.

46. Ambros $\mathrm{V}$, Lee RC, Lavanway A, Williams PT, Jewell D: MicroRNAs and other tiny endogenous RNAs in C. elegans. Curr Biol 2003, 13:807-818.

47. Conaco C, Otto S, Han JJ, Mandel G: Reciprocal actions of REST and a microRNA promote neuronal identity. Proc Natl Acad Sci USA 2006, 103:2422-2427.

48. Cao X, Pfaff SL, Gage FH: A functional study of miR-124 in the developing neural tube. Genes Dev 2007, 21:531-536.

49. Visvanathan J, Lee S, Lee B, Lee JW, Lee SK: The microRNA miR-124 antagonizes the anti-neural REST/SCP1 pathway during embryonic CNS development. Genes Dev 2007, 21:744-749.

50. Hébert JM, Fishell G: The genetics of early telencephalon patterning: some assembly required. Nat Rev Neurosci 2008, 9:678-685.

51. Giraldez AJ, Cinalli RM, Glasner ME, Enright AJ, Thomson JM, Baskerville S, Hammond SM, Bartel DP, Schier AF: MicroRNAs regulate brain morphogenesis in zebrafish. Science 2005, 308:833-838.

52. Raible F, Brand M: Divide et impera - the midbrain-hindbrain boundary and its organizer. Trends Neurosci 2004, 27:727-734.

53. Pi H, Chien CT: Getting the edge: neural precursor selection. J Biomed Sci 2007, 14:467-473.

54. Biryukova I, Asmar J, Abdesselem H, Heitzler P: Drosophila mir-9a regulates wing development via fine-tuning expression of the LIM only factor, dLMO. Dev Biol 2009, 327:487-496.

55. Bejarano F, Smibert P, Lai EC: miR-9a prevents apoptosis during wing development by repressing Drosophila LIM-only. Dev Biol 2010, 338:63-73.

56. Nolo R, Abbott LA, Bellen HJ: Senseless, a Zn finger transcription factor, is necessary and sufficient for sensory organ development in Drosophila. Cell 2000, 102:349-362.

57. Delaloy C, Gao F-B: MicroRNA-9 multitasking near organizing centers. Nat Neurosci 2008, 11:625-626.

58. Krichevsky AM, Sonntag KC, Isacson O, Kosik KS: Specific microRNAs modulate embryonic stem cell-derived neurogenesis. Stem Cells 2006, 24:857-864.

59. Zhao C, Sun G, Li S, Shi Y: A feedback regulatory loop involving microRNA-9 and nuclear receptor TLX in neural stem cell fate determination. Nat Struct Mol Biol 2009, 16:365-371.

60. Belmont LD, Mitchison TJ: Identification of a protein that interacts with tubulin dimers and increases the catastrophe rate of microtubules. Cell 1996, 84:623-631.

61. Lim LP, Lau NC, Garrett-Engele P, Grimson A, Schelter JM, Castle J, Bartel DP, Linsley PS, Johnson JM: Microarray analysis shows that some microRNAs downregulate large numbers of target mRNAs. Nature 2005, 433:769-773.

62. Makeyev EV, Zhang J, Carrasco MA, Maniatis T: The microRNA miR-124 promotes neuronal differentiation by triggering brain-specific alternative pre-mRNAsplicing. Mol Cell 2007, 27:435-448.

63. Arvanitis DN, Jungas T, Behar A, Davy A: Ephrin-B1 reverse signaling controls a post-transcriptional feedback mechanism via miR-124. Mol Cell Biol 2010, 30:2508-2517.

64. Cheng LC, Pastrana E, Tavazoie M, Doetsch F: miR-124 regulates adult neurogenesis in the subventricular zone stem cell niche. Nat Neurosci 2009, 12:399-408. 
65. Maiorano NA, Mallamaci A: Promotion of embryonic cortico-cerebral neuronogenesis by miR-124. Neural Dev 2009, 4:40.

66. Clark AM, Goldstein LD, Tevlin M, Tavaré S, Shaham S, Miska EA: The microRNA miR-124 controls gene expression in the sensory nervous system of Caenorhabditis elegans. Nucleic Acids Res 2010, 38:3780-3793.

67. Davis TH, Cuellar TL, Koch SM, Barker AJ, Harfe BD, McManus MT, Ullian EM: Conditional loss of Dicer disrupts cellular and tissue morphogenesis in the cortex and hippocampus. J Neurosci 2008, 28:4322-4330.

68. Xu XL, Li Y, Wang F, Gao FB: The steady-state level of the nervoussystem-specific microRNA-124a is regulated by dFMR1 in Drosophila. J Neurosci 2008, 28:11883-11889.

69. Berdnik D, Fan AP, Potter CJ, Luo L: MicroRNA processing pathway regulates olfactory neuron morphogenesis. Curr Biol 2008, 18:1754-1759.

70. Vo N, Klein ME, Varlamova O, Keller DM, Yamamoto T, Goodman RH, Impey S: A cAMP-response element binding protein-induced microRNA regulates neuronal morphogenesis. Proc Natl Acad Sci USA 2005, 102:16426-16431.

71. Yu JY, Chung KH, Deo M, Thompson RC, Turner DL: MicroRNA miR-124 regulates neurite outgrowth during neuronal differentiation. Exp Cell Res 2008, 314:2618-2633.

72. Edbauer D, Neilson JR, Foster KA, Wang CF, Seeburg DP, Batterton MN, Tada T, Dolan BM, Sharp PA, Sheng M: Regulation of synaptic structure and function by FMRP-associated microRNAs miR-125b and miR-132. Neuron 2010, 65:373-384.

73. Yoo AS, Staahl BT, Chen L, Crabtree GR: MicroRNA-mediated switching of chromatin-remodelling complexes in neural development. Nature 2009, 460:642-646.

74. Schratt G: MicroRNAs at the synapse. Nat Rev Neurosci 2009, 10:842-849.

75. Schaefer A, O'Carroll D, Tan CL, Hillman D, Sugimori M, Llinas R, Greengard P: Cerebellar neurodegeneration in the absence of microRNAs. J Exp Med 2007, 204:1553-1558.

76. De Pietri Tonelli D, Pulvers JN, Haffner C, Murchison EP, Hannon GJ, Huttner WB: miRNAs are essential for survival and differentiation of newborn neurons but not for expansion of neural progenitors during early neurogenesis in the mouse embryonic neocortex. Development 2008, 135:3911-3921.

77. Sokol NS, Xu P, Jan YN, Ambros V: Drosophila let-7 microRNA is required for remodeling of the neuromusculature during metamorphosis. Genes Dev 2008, 22:1591-1596.

78. Caygill $\mathrm{EE}$, Johnston LA: Temporal regulation of metamorphic processes in Drosophila by the let-7 and miR-125 heterochronic microRNAs. Curr Biol 2008, 18:943-950.

79. Karr J, Vagin V, Chen K, Ganesan S, Olenkina O, Gvozdev V, Featherstone DE: Regulation of glutamate receptor subunit availability by microRNAs. J Cell Biol 2008, 185:685-697.

80. Simon DJ, Madison JM, Conery AL, Thompson-Peer KL, Soskis M, Ruvkun GB, Kaplan JM, Kim JK: The microRNA miR-1 regulates a MEF-2dependent retrograde signal at neuromuscular junctions. Cell 2008, 133:903-915

81. Williams AH, Valdez G, Moresi V, Qi X, McAnally J, Elliott JL, Bassel-Duby R, Sanes JR, Olson EN: MicroRNA-206 delays ALS progression and promotes regeneration of neuromuscular synapses in mice. Science 2009, 326:1549-1554.

82. Martin KC, Casadio A, Zhu H, Yaping E, Rose JC, Chen M, Bailey CH, Kandel ER: Synapse-specific, long-term facilitation of aplysia sensory to motor synapses: a function for local protein synthesis in memory storage. Cell 1997, 91:927-938.

83. Barco A, Alarcon JM, Kandel ER: Expression of constitutively active CREB protein facilitates the late phase of long-term potentiation by enhancing synaptic capture. Cell 2002, 108:689-703.

84. Krol J, Busskamp V, Markiewicz I, Stadler MB, Ribi S, Richter J, Duebel J, Bicker S, Fehling HJ, Schübeler D, Oertner TG, Schratt G, Bibel M, Roska B, Filipowicz W: Characterizing light-regulated retinal microRNAs reveals rapid turnover as a common property of neuronal microRNAs. Cell 2010, 141:618-631.

85. Chandrasekar V, Dreyer JL: microRNAs miR-124, let-7 d and miR-181a regulate cocaine-induced plasticity. Mol Cell Neurosci 2009, 42:350-362.

86. Pietrzykowski AZ, Friesen RM, Martin GE, Puig SI, Nowak CL, Wynne PM, Siegelmann HT, Treistman SN: Post-transcriptional regulation of BK channel splice variant stability by miR-9 underlies neuroadaptation to alcohol. Neuron 2008, 59:274-287.
87. Lee Y, Samaco RC, Gatchel JR, Thaller C, Orr HT, Zoghbi HY: miR-19, miR101 and miR-130 co-regulate ATXN1 levels to potentially modulate SCA1 pathogenesis. Nat Neurosci 2008, 11:1137-1139.

88. Brown RH: Medicine. A reinnervating microRNA. Science 2009, 326:1494-1495.

89. Haramati S, Chapnik E, Sztainberg Y, Eilam R, Zwang R, Gershoni N, McGlinn E, Heiser PW, Wills AM, Wirguin I, L Rubin L, Misawa H, Tabin CJ, Brown R Jr, Chen A, Hornstein E: miRNA malfunction causes spinal motor neuron disease. Proc Natl Acad Sci USA 2010, 107:13111-13116.

90. Packer AN, Xing Y, Harper SQ, Jones L, Davidson BL: The bifunctional microRNA miR-9/miR-9* regulates REST and CoREST and is downregulated in Huntington's disease. J Neurosci 2008, 28:14341-14346.

91. Hébert SS, Horré K, Nicolaï L, Papadopoulou AS, Mandemakers W, Silahtaroglu AN, Kauppinen S, Delacourte A, De Strooper B: Loss of microRNA cluster miR-29a/b-1 in sporadic Alzheimer's disease correlates with increased BACE1/beta-secretase expression. Proc Natl Acad Sci USA 2008, 105:6415-6420.

92. Liu N, Olson EN: MicroRNA regulatory networks in cardiovascular development. Dev Cell 2010, 18:510-525.

93. Selbach M, Schwanhäusser B, Thierfelder N, Fang Z, Khanin R, Rajewsky N: Widespread changes in protein synthesis induced by microRNAs. Nature 2008, 455:58-63.

94. Baek D, Villén J, Shin C, Camargo FD, Gygi SP, Bartel DP: The impact of microRNAs on protein input. Nature 2008, 455:64-71.

95. Chi SW, Zang JB, Mele A, Darnell RB: Argonaute HITS-CLIP decodes microRNA-mRNA interaction maps. Nature 2009, 460:479-486.

96. Hafner $M$, Landthaler $M$, Burger $L$, Khorshid $M$, Hausser J, Berninger $P$, Rothballer A, Ascano M Jr, Jungkamp AC, Munschauer M, Ulrich A, Wardle GS, Dewell S, Zavolan M, Tuschl T: Transcriptome-wide identification of RNA-binding protein and microRNA target sites by PARCLIP. Cell 2010, 141:129-141.

97. Christodoulou F, Raible F, Tomer R, Simakov O, Trachana K, Klaus S, Snyman H, Hannon GJ, Bork P, Arendt D: Ancient animal microRNAs and the evolution of tissue identity. Nature 2010, 463:1084-1088.

98. Berezikov E, Thuemmler F, van Laake LW, Kondova I, Bontrop R, Cuppen E, Plasterk RH: Diversity of microRNAs in human and chimpanzee brain. Nat Genet 2006, 38:1375-1377.

doi:10.1186/1749-8104-5-25

Cite this article as: Gao: Context-dependent functions of specific microRNAs in neuronal development. Neural Development 2010 5:25.

\section{Submit your next manuscript to BioMed Central and take full advantage of:}

- Convenient online submission

- Thorough peer review

- No space constraints or color figure charges

- Immediate publication on acceptance

- Inclusion in PubMed, CAS, Scopus and Google Scholar

- Research which is freely available for redistribution 